\title{
Research on design of Tibetan cultural and creative products based on prototype theory
}

\author{
Zhang Shutao*, An Zonglin, Su Pengfei, and Su Jianning \\ School of Design Art, Lanzhou University of Technology, Lanzhou, Gansu, 730050, China
}

\begin{abstract}
Aiming at the problems of homogeneity, simplification and low cultural recognition of Tibetan cultural and creative products, design and application research are carried out in combination with prototype theory. Firstly, we determine the target product through fieldwork, and analyze the existing products in the market. Then through the analysis of Tibetan culture, using product semantic methods, we extract the pattern elements that match the semantic of the target product, and determine the design prototype. Finally, combining the prototype theory, we analyse of the design prototype to inspire the design, complete the innovative design of the product. Practice has shown that the use of prototype theory for product design can accurately identify Tibetan cultural symbols and excavate cultural connotations to promote the spread and development of Tibetan culture.
\end{abstract}

\section{Introduction}

Cultural and creative products, as a kind of cultural consumer goods, are the core of the development of the cultural industry. In recent years, they have aroused a lot in China and have been favored by the market. However, with the development of the cultural and creative industry, the phenomenon of homogenization and simplification of products has also appeared, and even imitation of cultural forms and direct texture applications of patterns have appeared, which leads to the sameness, the lack of product differentiation and cultural identification, and reduces consume desire ${ }^{[1-2]}$. Therefore, how to design cultural and creative products that better reflect cultural connotation has become an important issue to cultural and creative industry.

The Tibetan is one of the oldest ethnic groups where all people believe in religion. China has five major Tibetan areas, namely the Tibet Autonomous Region, Qinghai Tibetan District, Southern Gansu Tibetan Area, Tibetan Area of West of Sichuan and Yunnan Tibetan District. In recent years, with the advancement of the "Belt and Road" strategy, the cultural industry in Tibet is booming. However, due to its harsh natural conditions and backward economic foundation, the cultural and creative industry in Tibet still have a large gap compared with other developed regions ${ }^{[3]}$.

Based on what has been discussed above, this research will focus on Tibetan culture and use prototype theory to innovate the design method of Tibetan cultural and creative products, so that the products fully reflect the cultural connotation of Tibetan culture and provide ideas for the design of Tibetan cultural and creative products.

\section{Prototype theory}

The prototype theory was proposed by the famous Greek thinker and philosopher Plato more than 2000 years ago. And combined with Swiss psychologist Carl Gustav Jung's "collective unconscious" theory, it gradually penetrated into literature, architecture, design and other fields. It is collectively unconscious with high concentration and generality. In the field of design, prototype refers specifically to things that can inspire current design activities, and is a typical representation of a certain regional culture. It is stored in people's long-term memory, and has three characteristics: typicality, regionality and relative stability. When it comes to regional culture, the first reaction in people's minds can be used as a design prototype. Prototypes can be physical or non-physical, including morphological prototypes, color prototypes, ornamentation prototypes, functional prototypes, etc ${ }^{[4]}$. The use of prototype theory can better identify cultural characteristics and make the designed products better express cultural connotation.

The prototype theory was first applied in the field of cultural and creative design by Associate Professor Yi Jun from Hunan University. Taking Changsha Kiln as the research object, he summed up the design creativity mechanism based on the Prototype-Based Heuristics and the Prototype Matching ${ }^{[5]}$. Then Wang Fang and others took Huxiang culture as a design case to construct a prototype-driven integrated process model of cultural and creative product development and design ${ }^{[6]}$.

*Corresponding author's e-mail: 364725955@qq.com 


\section{Analysis of target product and prototype}

\subsection{Analysis of existing target products}

Through fieldwork in Southern Gansu Tibetan Area, visits to monasteries and shops, and literature collection, it was found that the prayer wheel is a necessary item for Tibetans to carry with themself. In addition to reciting the scriptures, Tibetan folk also read the scriptures in the manner of spinning prayer wheel. Each turn of the prayer wheel means reciting the scriptures once. Tibetan people express their piety to the Buddha by turning scripture, and at the same time they place their expectation of happiness and good wishes. This behavior of turning scripture has also become a typical representation of the religious culture and national culture.

Therefore, we take vehicle-mounted prayer wheel as research case, and analyzes the existing products through network data collection. There are various types of vehicle-mounted prayer wheel with three rotation modes: battery-powered, solar-powered and solar cell dual-drive. Due to the influence of Tibetan style, the overall is complicated with fine carving patterns and jewelry. Through investigation, some samples of the vehicle-mounted prayer wheel with high cultural recognition are selected and analyzed from the aspects of modeling and cultural background.

Case 1 (as shown in Figure 1): In Tibetan, the deer and the Falun are symbols of compassion and auspiciousness. The "Shuanglu Falun" appears in major monasteries. The product is taken as design prototype with its beautiful semantics to give the product an auspicious meaning that the item keeps running and breaks troubles under the premise of satisfying functionality. In terms of carving texture, the traditional

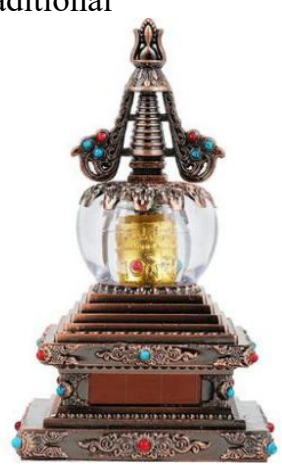

Figure 2. Case 2.
Tibetan auspicious eight-treasure pattern is used to make the product more ethnic. In terms of material, ABS plastic material is used to make the product more lightweight and drop-proof. And the ABS material is not easy to burn, so it is safer to put it on the dashboard of the car. The rotation mode adopts battery-powered rotation, which can make the product rotate more agile, but it will also increase the product cost accordingly, and the seismic performance is poor.

Case 2 (as shown in Figure 2): Stupa can be seen everywhere in Tibetan, is the places where the sacred relic have appeared and hold a very high position in the hearts of the Tibetan people. The product takes the overall outline of the Tibetan stupa as design prototype, making the product more solemn and sedate in the vision with unique Tibetan charm. The whole product takes the common plant patterns of Tibetans as pattern carving, and is decorated with precious stones to make the product more gorgeous and complicated. The product material is made of zinc alloy, which has a strong sense of modernity and has good corrosion resistance and wear resistance. The product adopts solar-powered rotation to increase the safety and reliability of the product.

Case 3 (as shown in Figure 3): The white elephant pattern in the auspicious animal pattern in the Tibetan, also known as the "white elephant king god of wealth", has the meaning of conquering evil spirits and attracting wealth. The product takes the white elephant pattern as the design prototype to give the product a good meaning of fortune. The overall shape of the product extracts the white elephant form to make the product more unique. The material is made of zinc alloy, and its rotation mode is dual-energy drive of battery and solar energy. It changes the previous single power supply method and makes the product more efficient.
Figure 1. Case 1.

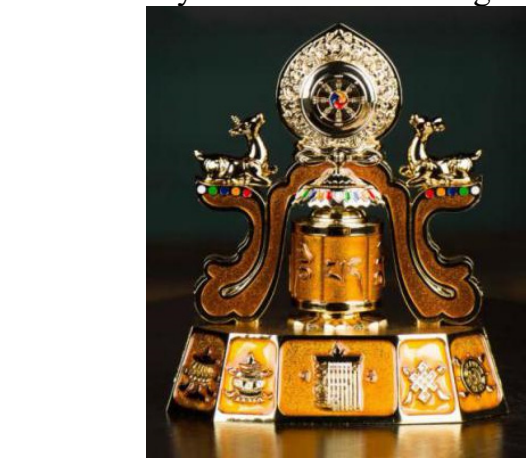

\subsection{Analysis of target product semantic}

Product semantics is an important part of semiotics. Its essence is to study the mapping relationship between design symbols and their symbolic meaning. In the field of product design, product semantics are usually divided into extensional semantics and internal semantics. And internal semantics, conveying the culture and values behind the product ${ }^{[7]}$, is a more multidimensional and more perceptual expression than extensional semantics.
Cultural and creative products need to take root in regional culture, and their purpose is to inherit and develop local culture. Combining product semantics for cultural and creative product design, and cultural screening through semantic matching, it makes products better and more accurate mapping culture, and also allows designers and users to achieve uniform recognition in the cultural expression of products.

The vehicle-mounted prayer wheel is mainly to combine the Tibetan turning scripture culture and vehicle-mounted products. It's not only reflects the 
functional value of products but also satisfies the spiritual pursuit of Tibetan people. Its extended semantics are mainly reflected in the modeling and color of the product. In terms of modeling, the product can be designed into a square shape to give a sense of stability and security. The overall modeling is complicated. The complex decoration gives a sense of luxury. In terms of color, traditional Tibetan color schemes should be selected, such as red giving a sense of enthusiasm, white giving a sense of quietness and neatness, and gold giving a sense of luxury. Its internal semantics are mainly reflected in the cultural connotation of Tibetans, and the prayer wheel is an essential thing for Tibetan Buddhism. Combined with vehicle-mounted function, taking into account the product context requirements, and combining the product's inherent and symbolic role, the product should have the semantics of travel safety, smoothness, comfort, happiness and so on. Screening Tibetan cultural elements through the extension and internal of products can make products more culturally unified.

\subsection{Analysis of Tibetan cultural symbols}

The Tibetan is a nation with a long history and cultural heritage. Its pattern can be traced back to the Neolithic Age more than 4000 years ago. Affected by the ideas of Tibetan Buddhism, the auspicious patterns of Tibetans reflect their values and religious beliefs. The patterns cover the sun, moon, stars, mountains, rivers, flowers, birds, religion and folk customs ${ }^{[8]}$. Its theme can be divided into characters, utensils, animals, plants, symbols, geometric patterns, mandala and stupa patterns ${ }^{[9]}$.
According to the description of the product semantics above, the patterns that conform to the semantics of the vehicle-mounted prayer wheel are selected from Tibetan culture, including the Tibetan wind-horse pattern, the eight-treasure pattern, and the ten-phase free pattern, etc, among which the most representative is the Tibetan wind-horse pattern. When it comes to Tibetans, the first thing comes to mind is the prayer flags painted with wind-horse pattern. Tibetan pin their faith and hope by spreading prayer flags and hanging prayer flags, and bring peace and auspiciousness to passers-by.

In this study, wind-horse pattern were selected as the design prototype. Through systematic analysis, combined with the prototype theory, we complete product innovation design.

\section{Product design}

\subsection{Analysis of target product and cultural element characteristics}

From the perspective of emotional design, the culture is divided into three levels: external, behavior and internal. By analyzing the characteristic attributes of the vehicle-mounted prayer wheel (target product) and the wind-horse pattern (prototype), the target product and the design prototype are related through three levels of characteristics, as shown in Table 1. It's conducive to obtaining the key information of the design prototype and providing ideas for subsequent product design.

Table 1. The relationship between vehicle-mounted prayer wheel and wind-horse pattern.

\begin{tabular}{|c|c|c|}
\hline \multirow{5}{*}{$\begin{array}{l}\text { External } \\
\text { level } \\
\text { feature } \\
\text { association }\end{array}$} & Form & $\begin{array}{l}\text { The overall outline shape of the white horse with three treasures in the } \\
\text { wind-horse pattern meets the modelling requirements of the vehicle-mounted } \\
\text { prayer wheel. }\end{array}$ \\
\hline & Color & $\begin{array}{l}\text { The prayer flags have five colors with different symbolic meanings, which can } \\
\text { be transformed and applied according to the material of the vehicle-mounted } \\
\text { prayer wheel. }\end{array}$ \\
\hline & Structure & Both are up-down structure with similar basic constituent elements. \\
\hline & Ornamentation & $\begin{array}{l}\text { The prototype is a ornamentation, and can be introduced into a 3-D } \\
\text { application. }\end{array}$ \\
\hline & Texture & $\begin{array}{l}\text { The texture of wind-horse can be added to the surface of the prayer wheel to } \\
\text { fully reflect the Tibetan culture. }\end{array}$ \\
\hline \multirow[t]{2}{*}{$\begin{array}{l}\text { Behavior } \\
\text { level } \\
\text { feature } \\
\text { association }\end{array}$} & Usage mode & $\begin{array}{l}\text { In the wind-horse pattern, the horse is the wind carrying the prayers and } \\
\text { blessings of the people. The prayer flags painted with the wind-horse pattern } \\
\text { gone with wind spread the faith and hope of Tibetan, and pass peace to the } \\
\text { people. These modes of behavior can be combined with the vehicle-mounted } \\
\text { prayer wheel. But the vehicle-mounted prayer wheel needs to be placed on the } \\
\text { instrument table of the car, so its stability needs to be considered. }\end{array}$ \\
\hline & $\begin{array}{l}\text { Structure } \\
\text { function }\end{array}$ & $\begin{array}{l}\text { The wind-horse is a flat pattern, and the vehicle-mounted prayer wheel is a } \\
\text { functional product. On the basis of its up-down structure, it's necessary to } \\
\text { consider the rotation mode of prayer wheel and the position of the scriptures. }\end{array}$ \\
\hline \multirow{2}{*}{$\begin{array}{l}\text { Internal } \\
\text { level } \\
\text { feature } \\
\text { association }\end{array}$} & $\begin{array}{l}\text { Religious } \\
\text { moral }\end{array}$ & $\begin{array}{l}\text { The wind-horse culture has a lofty position in the minds of Tibetan. The } \\
\text { wind-horse pattern is added to the design of the vehicle-mounted prayer } \\
\text { wheel, and the religious meaning of the wind-horse pattern and the prayer } \\
\text { wheel are used to make the product express people's desire for travel safety. }\end{array}$ \\
\hline & $\begin{array}{l}\text { Emotional } \\
\text { experience }\end{array}$ & $\begin{array}{l}\text { The prayer wheel plays an important role in the lives of Tibetan. In the design, } \\
\text { the prayer wheel is combined with the vehicle-mounted product, and the }\end{array}$ \\
\hline
\end{tabular}




\begin{tabular}{l|l|l}
\hline & $\begin{array}{l}\text { wind-horse culture is integrated into product. It not only satisfies the } \\
\text { emotional dependence of reading the scriptures for travel safety anytime and } \\
\text { anywhere, but also conforms to the usage habit of contemporary people. }\end{array}$ \\
\cline { 2 - 3 } & $\begin{array}{l}\text { Cultural } \\
\text { attribute }\end{array}$ & $\begin{array}{l}\text { The typical wind-horse pattern in the traditional Tibetan auspicious patterns is } \\
\text { applied to the design of the vehicle-mounted prayer wheel, so that the } \\
\text { products have more Tibetan cultural attributes. }\end{array}$ \\
\hline
\end{tabular}

Through the correlation analysis of the characteristics of the target product and the design prototype, it can be seen that the overall modelling design of the vehicle-mounted prayer wheel can apply the outline shape of the white horse with three treasures in the wind-horse pattern. The color can be selected according to the five colors of the prayer flags and the material requirements of the product. The structure of the product should be up-down structure to ensure the stability of the product. The rotation mode of prayer wheel and the position of scriptures should be considered in terms of use and structural function.

\subsection{Characteristic analysis of prototype}

In terms of element composition, layout and religious moral, the wind-horse pattern is composed of white horses, quartet god beast, scripture and eight-treasure auspicious patterns. The white horses is the core of the prayer flags, with up-down structure. The piggybacking "three-color Ruyibao", symbolize the prosperity of wealth, representing Buddha, Dharma and Sangha, has the meaning of auspicious that encourages people to realize their wishes. The gorgeous horse with running posture means that it will bring local people a safe, prosperous, auspicious and harmonious light ${ }^{[10-11]}$. The perimeter of the prayer flags is painted with roc, dragon, lion and tiger. The whole flag is rich in patterns, and there are few blanks. In addition to the main body of the horse and the quartet god beast, there are also Tibetan eight-treasure patterns and some scriptures painted around them.

There are five colors on prayer flags, including blue, white, red, green and yellow. Each color has a symbolic meaning. Blue is a symbol of quiet, wisdom, justice, courage, wit. White is a common color of Tibetan. The white Hada represents purity and goodness, and is also a symbol of auspiciousness and happiness. Tibetan express their welcome and blessings to guests through the ceremony of offering Hada. Red is also can be seen everywhere in the Tibetan. The monastery buildings and robes worn by monks are all red. Influenced by Tibetan Buddhism, red is a symbol of enthusiasm, prosperity, and justice, and it also shows the meaning of fraternity, charity, and auspiciousness. Green is a symbol of femininity and peace, and also implies youth vitality and life extension. Yellow is a symbol of light and hope, and has the meaning of wealth and harvest.

\subsection{Sketch and scheme}

Through the analysis of the characteristics of the design prototype, the concept sketches are drawn using design methods such as decomposition, reconstruction, and simplification, as shown in Figure 4. In the design process, we do feature matching on the conceptual schemes and design prototypes, select the innovative schemes with high matching degree and rich cultural connotation for in-depth design, and complete the final scheme. It's also a process of prototype matching to test whether the final scheme accurately expresses the Tibetan cultural connotation.
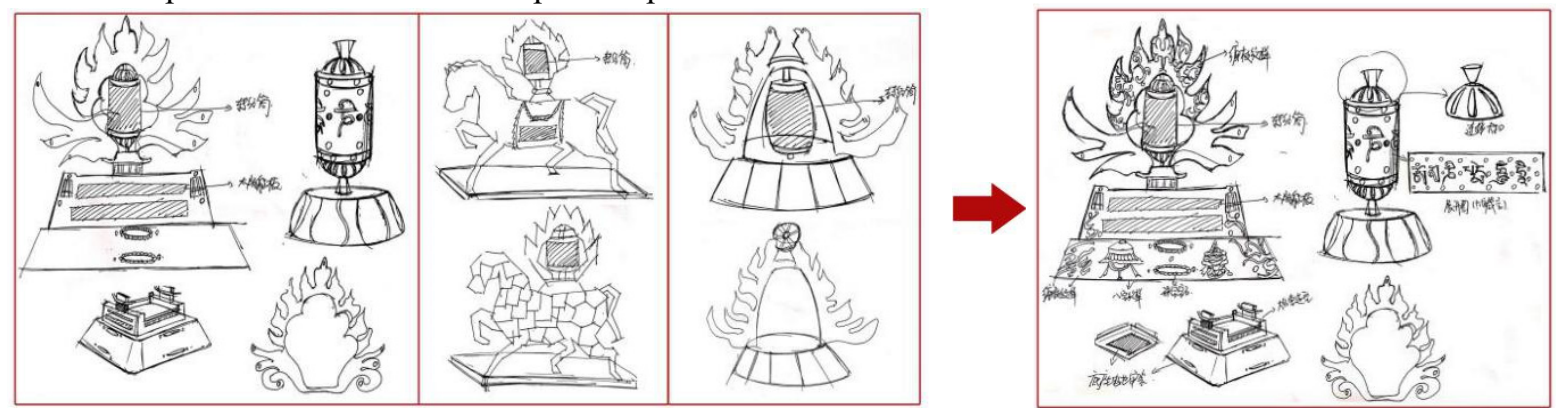

Figure 4. Screening of conceptual schemes (partial).

\section{4 product design}

According to the conceptual scheme, combined with
Tibetan culture, we constantly evaluate and improve the product shape. And the final scheme is shown in Figure 5. 


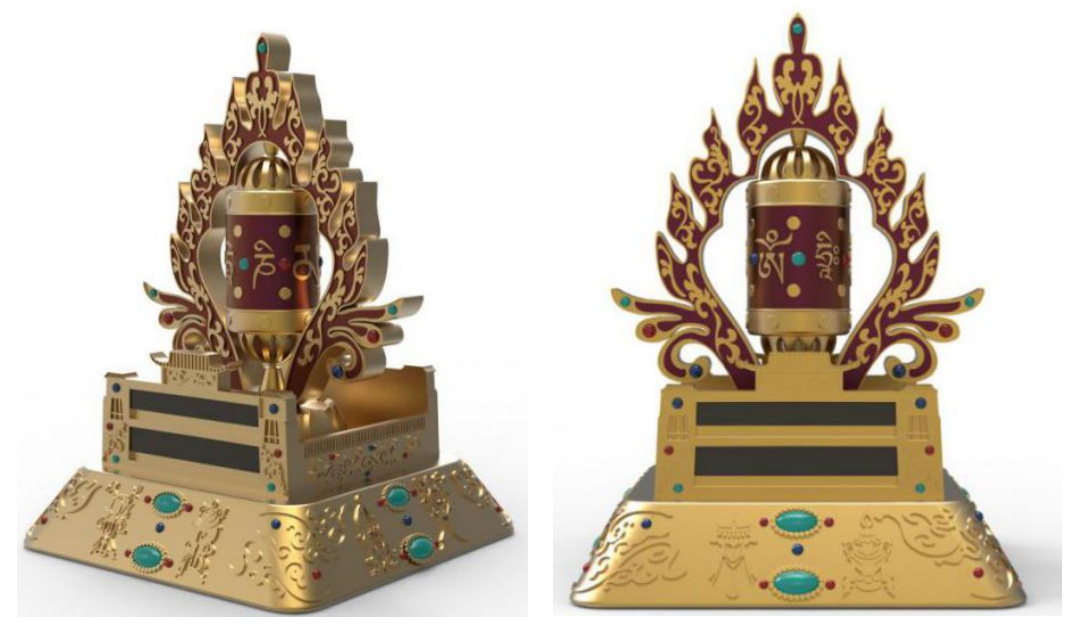

Figure 5. Final scheme.

We adopt the "three-color Ruyibao" carried by the white horse in the wind-horse pattern as the overall outline shape to give products the meaning of peace and prosperity. The scheme gives cultural connotation to the product, meets the emotional needs of vehicle products, and expresses users' good wishes for safe and smooth travel. In the middle part of the product, the outline shape of the Main Assembly Hall, the representative building of Labrang Monastery in Southern Gansu Tibetan Area, is added to make the product more culturally distinctive of Gannan Tibetans. The overall shape of the product adopts the up-down structure. And the base is designed to be square, which increases its stability and gives users a safe experience.

In terms of the product texture, we select the Tibetan auspicious eight-treasure pattern and the Entangled Floral Branch pattern. The ornament of tricolor gem makes the whole product complex and gorgeous, with Tibetan style. At the same time, we borrow the semantic connotation of the auspicious eight-treasure pattern to give the product more auspicious and cultural charm. The color of the product is red and gold, which are in line with the Tibetan emotional pursuit of color and gives users warm, rich and auspicious visual experience. The rotation mode of the product adopts solar and battery dual-drive energy supply to improve the rotation efficiency.

\section{Conclusion}

In this study, we analyze Tibetan cultural elements, and extracts its pattern prototype through the investigation of existing products and the analysis and selection of product semantics. And according to the prototype theory, we complete the design of the Tibetan vehicle-mounted prayer wheel. The design practice shows that the final scheme has a high degree of Tibetan cultural recognition, which can cause cultural resonance between consumers and products. The study provides a new method for the design of Tibetan cultural and creative products to help the inheritance and development of Tibetan culture.

\section{Acknowledgements}

The authors would like to acknowledge the financial support from the Department of Education of Gansu Province (University Innovation Fund Project of Gansu Province, 2020, Research on innovative design method and theoretical system of cultural and tourism products), the National Natural Science Foundation of China (Grant No. 51705226), the Science and Technology Department of Gansu Province (Grant No. 18CX4JN022).

\section{References}

1. Zou Zijing, Li Xueyan, Di Wenhe. (2019) Research on the cultural and creative product design of Nanjing brocade. Popular Literature and Art, (14): 121-122.

2. Zheng Shuai. (2020) The creative strategies of graphic cultural and creative products. Design, 33(07): 84-86.

3. Luo Li. (2018) On the development of Tibetan cultural industry in the new era. China Tibetology, (01): 24-25.

4. Wang Fang. (2018) Research on Prototype driven Cultural and Creative Product Design. Industrial Design, (08): 46-47.

5. YI Jun. (2014) Acquisition and Digital Representation of Changsha Kiln Things Prototype. Hunan University.

6. Wang Fang. (2017) Huxiang culture creative products design based on prototype driven. Hunan University.

7. Zhang Jiaqi, Dai Yulu. (2018) Research and Application of Cultural Derivatives Design Based on Product Semantics. Art Panorama, (11): 96-97.

8. Wang Yanqiu. (2018) The Application of Tibetan traditional auspicious patterns in the development of Tibetan family textile supporting products. Xi'an Polytechnic University.

9. Zhou Aimin, OuYang Jinyan, Li Fenqiang. (2014) 
The Cultural Connotations of Auspicious Patterns in Tibetan Furniture. Furniture, 35(02): 61-65.

10. Tong Fulei, Jiang Yue. (2018) An analysis of the graphic pattern of "Wind-Horse" in Gannan Tibetan. Popular Literature and Art, (23): 63-64.

11. Wang Lijuan, Liu Ruipu. (2013) Wind Horse-A Relic with the Same Structure of Tibetan and Han Culture. Art \& Design Research, (01): 86-88. 